Article

\title{
High Performance and Sustainable Copper-Modified Hydroxyapatite Catalysts for Catalytic Transfer Hydrogenation of Furfural
}

\author{
Balla Putrakumar ${ }^{1, *(\mathbb{D})}$, Prem Kumar Seelam ${ }^{2} * * \mathbb{D}$, Ginjupalli Srinivasarao ${ }^{3}$, Karthikeyan Rajan ${ }^{1}$, \\ Rajendiran Rajesh ${ }^{4}$, K. Ramachandra Rao ${ }^{5}\left(\mathbb{C}\right.$ and Tongxiang Liang ${ }^{1, *}$ \\ 1 College of Rare Earths (CoRE), Jiangxi University of Science and Technology, Ganzhou 341000, China; \\ karthikeyan148@yahoo.com \\ 2 Environmental and Chemical Engineering Research Unit, Faculty of Technology, University of Oulu, \\ P.O. Box 4300, 90014 Oulu, Finland \\ 3 Department of Basic Science and Humanities, Swarnandhra College of Engineering and Technology, \\ Narasapur 534280, India; gsrao260@gmail.com \\ 4 Department of Chemistry, Pondicherry University, Puducherry 605014, India; rrajchem7@gmail.com \\ 5 Crystal Growth \& Nano Research Centre, Department of Physics, Government College (Autonomous), \\ Rajahmundry, Andhra Pradesh 533105, India; drkrcr@gmail.com \\ * Correspondence: bputrakumar@yahoo.com (B.P.); prem.seelam@oulu.fi (P.K.S.); txliang@jxust.edu.cn (T.L.); \\ Tel.: +86-0797-8312733 (B.P. \& T.L.); +358-440780045 (P.K.S.)
}

Received: 30 July 2020; Accepted: 24 August 2020; Published: 11 September 2020

\begin{abstract}
Designing and developing non-noble metal-based heterogeneous catalysts have a substantial importance in biomass conversion. Meerwein-Ponndorf-Verley (MPV) reaction is a significant pathway for eco-friendly catalytic transfer hydrogenation (CTH) of biomass derived furfural into furfuryl alcohol. In this work, a series of copper-supported hydroxyapatite (HAp) catalysts with different copper loadings (2-20 wt.\%) were prepared by a facile impregnation method and tested in the reduction of furfural to furfuryl alcohol using 2-propanol as a hydrogen donor. The structural and chemical properties of the synthesised catalysts were analysed by using various techniques (XRD, $\mathrm{N}_{2}$ sorption, SEM, TEM, UV-DRS, ICP, FTIR, TPR, TPD- $\mathrm{CO}_{2}$ and $\mathrm{N}_{2} \mathrm{O}$ titration). The effect of copper loading was found to be significant on the total performance of the catalysts. The results demonstrate that 5CuHAp catalyst possess highly dispersed copper particles and high basicity compared to all other catalysts. Overall, 5CuHAp exhibited highest conversion $(96 \%)$ and selectivity $(100 \%)$ at $140{ }^{\circ} \mathrm{C}$ at $4 \mathrm{~h}$ time on stream. The optimised reaction conditions were also determined to gain the high activity.
\end{abstract}

Keywords: catalytic hydrogen transfer; furfural; furfuryl alcohol; copper

\section{Introduction}

Energy and chemical intermediates are primarily derived from conventional sources such as natural gas, oil and coal. This causes, exacerbation of environmental problems and depletion of resources [1]. There is an urgent need to analyse the renewability, economy and inexhaustible substitutes that can produce equal or higher energy yields to replace and avoiding usage of fossil fuels. Biomass-derived products often expose superior qualities related to the environment than their fossil fuel-based counterparts [2,3].

Furfural (FA) is widely used platform molecule which is derived from lignocellulosic biomass via acid hydrolysis [4]. FA is a versatile starting material for many intermediate chemicals, monomers and fuels [5]. Catalytic transformation of biomass-based furfural is one of the efficient valorisation 
processes that can offer in producing useful fuels, polymers and fuel additives such as ethyl levulinate, 2-methyl tetrahydrofuran, $\delta$-valerolactone, 2-methyl furan and ethyl furfuryl ether [6,7]. Direct transformation of furfural into furfuryl alcohol, furans and methyl furan via metal-catalysed hydrogenation, decarbonylation and reduction process is a key and important commercial application in producing wider range of derivatives [8].

Furfuryl alcohol (FAOL) has been used in rocket fuels which combust immediately and energetically when contacted with oxidisers [9]. FAOL is used in improving the moisture-dimensional stability, hardness, decay and insect resistance for the wood and furniture materials [10]. In polymer industry, it is most used in the fabrication of thermostat polymers, production of various synthetic fibres, rubbers-resins and liquid resins in ceramic industry. It is also used as a starting material for various industrial products such as lubricants, lysine, plasticisers, dispersing agents, vitamin $C$ and agro-chemicals [11,12].

Catalytic transformation of FA to FAOL can be achieved either via gas or liquid phase reactions, later one is advantageous than the former in terms of energy consumption and product selectivity [13]. In literature, two main synthesis approaches were reported for liquid phase hydrogenation of FA to FAOL. The first approach describes that dihydrogen gas $\left(\mathrm{H}_{2}\right)$ as a H-donor, exhibits superior hydrogenation efficiency over the transition metal catalysts, preferably over noble metals $(\mathrm{Au}, \mathrm{Pd}$, $\mathrm{Pt}, \mathrm{Ru}, \mathrm{Rh}$ and $\mathrm{Re}$ ) [14-18]. However, in the first approach, the use of pure hydrogen gas has several drawbacks including the need of costly infrastructure and the difficulty of transportation, safety and efficient storage. Second approach is simpler in terms of required laboratory equipment. The alcohols or formic acid was used as $\mathrm{H}$-donors instead of pure $\mathrm{H}_{2}$ and also acts as a solvent media in liquid phase reaction $[19,20]$.

CTH of FA has been widely investigated over various materials such as metal-based catalysts supported on oxides, carbon, zeolites and other promising support materials [21-27]. Most commonly used basic oxides in particular $\mathrm{MgO}, \mathrm{CaO}$ and mixed oxides have been developed for MPV reaction, which are inexpensive, commercially available and environmentally benign [28]. In one study, Solera et al. demonstrated that basicity is a key factor that plays an important role in MPV reaction than acidity [29]. Many promising support materials were optimised and studied in furfural hydrogenation in combination with $\mathrm{Cu}$. A bifunctional activity was presented by the $\mathrm{Cu}$-supported mixed oxides such as zeolites, $\mathrm{MgO}-\mathrm{Al}_{2} \mathrm{O}_{3}, \mathrm{CaO}$ and $\mathrm{CeO}_{2}-\mathrm{ZrO}_{2}$. Wang et al. reported the effect of support in specific acidity type such as $\mathrm{Cu} / \mathrm{ZSM}-5$ and $\mathrm{Cu} / \mathrm{Al}_{2} \mathrm{O}_{3}$ resulted in the formation of oligomers and over $\mathrm{Cu} / \mathrm{MgO}$ basic catalyst which had a better mass balance and reaction performance towards FAOL [30]. Recently, Fan et al. suggested that the basic mixed oxide $\gamma-\mathrm{Fe}_{2} \mathrm{O}_{3} @ \mathrm{HAP}$ catalyst had dual functionality, first hydrogen transfer from 2-propanol, and then $\mathrm{H}_{2}$ to FA [31]. Wenjie Shen et al. reported that $\mathrm{Cu} / \mathrm{La}_{2} \mathrm{O}_{3}$ catalyst exhibited high activity in the transfer dehydrogenation of primary alcohols and also stated that the effective conversion is mainly due to the high basicity of the catalyst [32]. Further, the proton abstraction was favoured by $\mathrm{La}_{2} \mathrm{O}_{3}$ under anaerobic conditions and the $\mathrm{Cu}$ particles are needed for hydrogen transfer to intermediate species.

Both noble $(\mathrm{Pt}, \mathrm{Ru}, \mathrm{Pd})$ and non-noble $(\mathrm{Ni}, \mathrm{Co}, \mathrm{Cu})$ based metal catalysts show good performance in catalytic FA hydrogenation [33,34]. Because of their cost and availability, non-noble transition metal catalysts are feasible for the future industrial applications. Among all the catalysts reported in the literature, $\mathrm{Cu}$-based catalysts presented as the promising choice for selective hydrogenation of furfural due to moderately high activity compared to noble metal catalysts and cost effective $[21,35,36]$. It is known that the $\mathrm{Cu}-\mathrm{Cr}$ catalyst was used in the industrial production of FA as it has best features [37]. According to environmental point of view $\mathrm{Cr}$ is toxic in nature, hence, non-chromium-based $\mathrm{Cu}$ catalysts were developed for both gas and liquid-phase hydrogenation. There are several challenges that still exist in developing sustainable and eco-friendly catalysts for the catalytic hydrogenation of FA. Henceforth, a sustainable and efficient catalyst support is needed in combination with robust $\mathrm{Cu}$ for selective catalytic hydrogenation of FA. In this context, we introduced hydroxyapatite support for $\mathrm{Cu}$ catalyst with simple preparation methods and precise $\mathrm{Cu}$ loading. The calcium-hydroxyapatite 
$\left(\mathrm{Ca}_{10}\left(\mathrm{PO}_{4}\right)_{6}(\mathrm{OH})_{2}\right)$, which is commonly known as hydroxyapatite (HAp), is a naturally occurring inorganic material known for being a basic support catalyst with cationic exchange properties for various applications [38]. Recently, HAp has attracted considerable attention as a catalyst-support material for transition metal-catalysed reactions [39,40].

In the present work, CuHAp catalysts were synthesised by a facile preparation method and tested in catalytic transfer hydrogenation of furfural to furfuryl alcohol using 2-propanol as hydrogen donor and solvent. The physico-chemical and morphological properties of the synthesised catalysts were obtained by various techniques including XRD, $\mathrm{N}_{2}$ sorption, SEM, TEM, UV-DRS, ICP, FTIR, TPR, TPD- $\mathrm{CO}_{2}$ and $\mathrm{N}_{2} \mathrm{O}$ titration. It was found that basicity and active $\mathrm{Cu}$ surface area had a great impact on the catalytic performances. The influences of reaction parameters including catalyst loading, temperature, time and $\mathrm{N}_{2}$ initial pressure were systematically investigated in detail. Finally, the recyclability of the best-performed catalyst was also studied.

\section{Results and Discussion}

\subsection{Characterisation}

Figure 1 shows the X-ray diffraction patterns of pure HAp and Cu-modified HAp catalysts. Well defined diffraction characteristics were observed for pure HAp support and matched with reference patterns of JCPDS Ref. 09-0432 [41]. After Cu loading on HAp support, the XRD patterns were compared with the pure HAp support. However, the absence of $\mathrm{Cu}$ peaks for the samples with 2 and $5 \mathrm{wt} . \%$ loading was evident because of the fact that small crystallites and a highly dispersed $\mathrm{CuO}$ phase was formed over the HAp support. Above $5 \mathrm{wt} . \%$ copper loading, the reflections at the $2 \theta$ values of $35.57^{\circ}$ and $38.67^{\circ}$ are broader due to the appearance of copper oxide phase and the corresponding planes are (11-1) and (111), respectively [42]. With further increase in copper loading up to $20 \mathrm{wt} . \%$, the peak intensity of $\mathrm{CuO}$ was found to increase to a greater extent. This designates that the increase in copper loading leads to the growth of $\mathrm{CuO}$ crystallites. Absence of any other $\mathrm{Cu}$ phase was evident in different $\mathrm{Cu}$ loading on HAp support which can be seen in the XRD pattern.

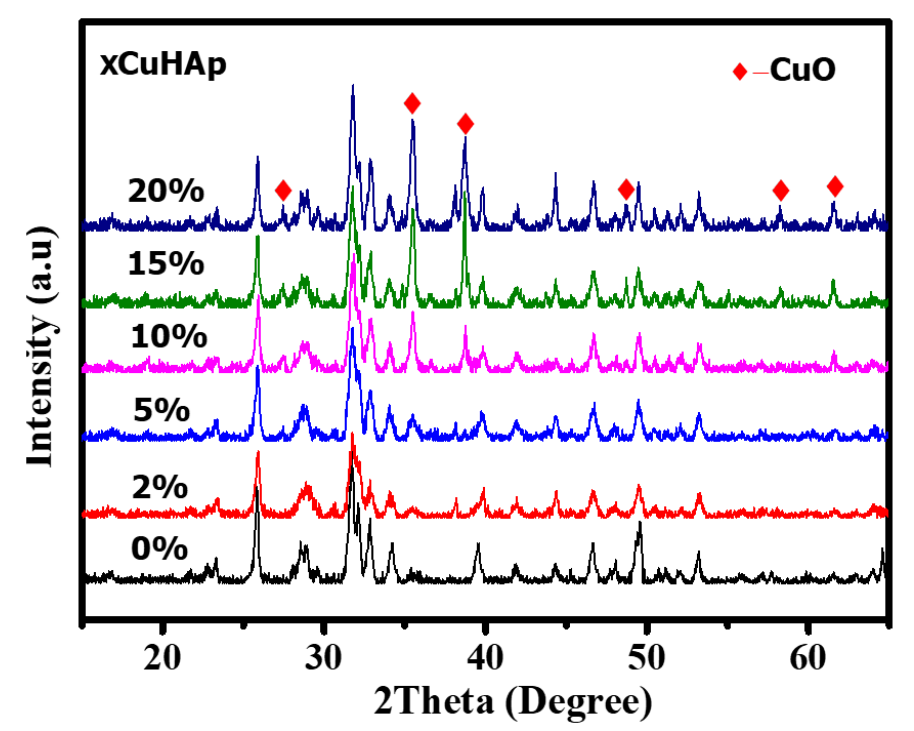

Figure 1. X-ray diffractograms of CuHAp catalysts with different $\mathrm{Cu}$ loadings.

The FTIR spectra of pure HAp and the Cu-supported catalysts were analysed in the range of wavelength $400-4000 \mathrm{~cm}^{-1}$, as shown in Figure 2. The strong characteristic functional groups on HAp are phosphate and hydroxyl groups. In theory, four kinds of vibrational modes are present for phosphate ions such as $v_{1}, v_{2}, v_{3}$ and $v_{4}$ [41]. All these modes were observed for all catalysts that are intrinsically infrared active in nature. Two intensive peaks at $500-700 \mathrm{~cm}^{-1}$ and $900-1200 \mathrm{~cm}^{-1}$ 
ranges were observed. The absorption band $\left(v_{1}\right)$ at $\sim 962 \mathrm{~cm}^{-1}$ is related to P-O symmetric stretching. Similarly, the band $\left(v_{2}\right)$ with weak intensity at $\sim 472 \mathrm{~cm}^{-1}$ is a characteristic peak of O-P-O bending vibrations. The IR band $\left(v_{3}\right)$ observed at $\sim 1040 \mathrm{~cm}^{-1}$ was due to the asymmetric stretching vibrations of P-O phosphate group. The intense band $\left(v_{4}\right)$ was observed in the region of $500-700 \mathrm{~cm}^{-1}$ is due to $\mathrm{P}-\mathrm{O}$ symmetric and asymmetric bending modes of $\mathrm{P}=\mathrm{O}$ bond. The low site symmetry bonding of the molecule causes splitting of vibration band $\left(v_{4}\right)$. The $\mathrm{OH}$ stretching vibration of water molecules was evident and the corresponding broad peak was appeared at $3440 \mathrm{~cm}^{-1}$ wavelengths. The sharp and low intense band at $3570 \mathrm{~cm}^{-1}$ related to the $\mathrm{O}-\mathrm{H}$ vibration modes hosted by the hydroxyapatite lattice.

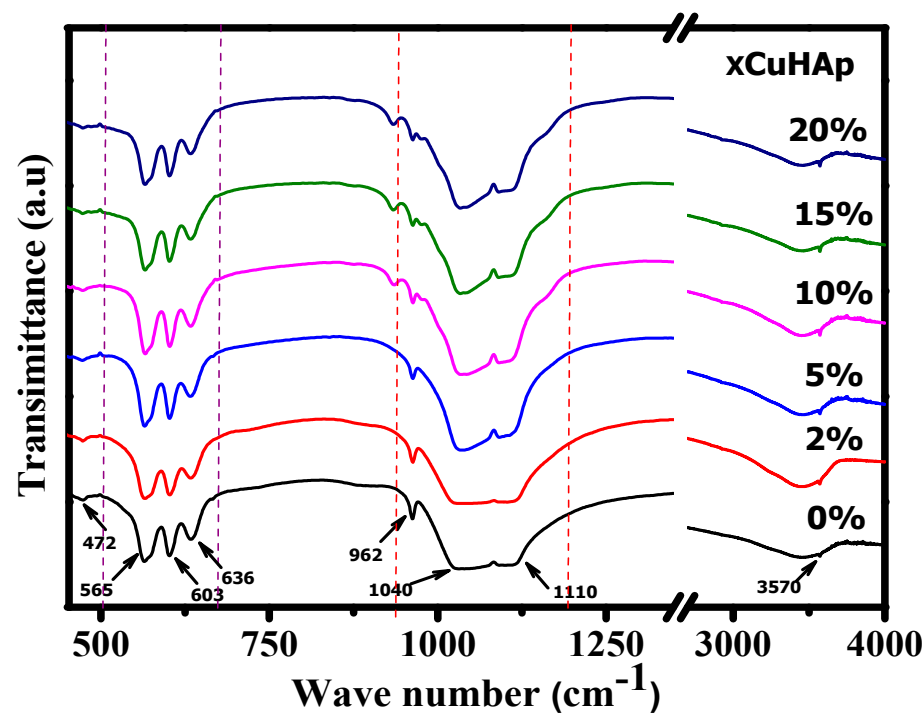

Figure 2. FTIR spectra of CuHAp catalysts with different $\mathrm{Cu}$ loadings.

The textural properties of CuHAp catalysts were investigated by nitrogen physisorption measurements and results are reported in Table 1. In case of pure HAp sample, the measured specific surface area found to be $76 \mathrm{~m}^{2} \cdot \mathrm{g}^{-1}$ which is the highest BET value compared to rest of the catalysts. From Table 1, it is clearly shown that after $\mathrm{Cu}$ incorporation, the surface areas of all $\mathrm{Cu}$-modified are lower than the pure HAp support. The surface area is decreased with $\mathrm{Cu}$ loading mainly due to the existence of $\mathrm{Cu}$ in bulk and covered on the surface of the HAp matrix.

Table 1. Catalytic properties from ICP, BET, $\mathrm{N}_{2} \mathrm{O}$ titration and $\mathrm{H}_{2}$-TPR results of CuHAp catalysts with different $\mathrm{Cu}$ loadings were summarised.

\begin{tabular}{cccccc}
\hline Catalyst & $\begin{array}{c}\mathbf{C u} \\
(\mathbf{w t .} \%)^{\mathbf{a}}\end{array}$ & $\begin{array}{c}\text { BET Surface } \\
\text { Area }\left(\mathbf{m}^{\mathbf{2}} / \mathbf{g m}\right)^{\mathbf{b}}\end{array}$ & $\begin{array}{c}\mathbf{C u} \\
\text { Surface Area }\left(\mathbf{m}^{\mathbf{2}} / \mathbf{g m}\right)^{\mathbf{c}}\end{array}$ & $\begin{array}{c}\text { Particle Size } \\
(\mathbf{n m})^{\mathbf{c}}\end{array}$ & $\begin{array}{c}\mathbf{H}_{2} \text { Uptake } \\
(\boldsymbol{\mu m o l} / \mathbf{g})^{\mathbf{d}}\end{array}$ \\
\hline HAp & - & 76 & - & - & - \\
2CuHAp & 1.81 & 62 & 204 & 3.3 & 51 \\
5CuHAp & 4.57 & 52 & 210 & 3.20 & 127 \\
10CuHAp & 8.9 & 46 & 143 & 4.70 & 152 \\
15CuHAp & 14.1 & 43 & 92 & 7.30 & 160 \\
20CuHAp & 18.7 & 37 & 62 & 10.8 & 174 \\
\hline
\end{tabular}

${ }^{a}$ Results from ICP-OES, ${ }^{b}$ results from BET measurements; ${ }^{\mathrm{c}}$ results from $\mathrm{N}_{2} \mathrm{O}$ titration; ${ }^{\mathrm{d}}$ results from $\mathrm{H}_{2}$-TPR.

The $\mathrm{N}_{2} \mathrm{O}$ titration experiments were performed to find out the average particle size and active $\mathrm{Cu}$ surface area of CuHAp catalysts and the results are tabulated in Table 1. Increase in copper surface area was evident with $\mathrm{Cu}$ loading from 2 to $5 \mathrm{wt} . \%$ and the average particle size was found to be smaller up to $5 \mathrm{wt} . \% \mathrm{Cu}$ loading. Hence, at low $\mathrm{Cu}$ loadings i.e., up to $5 \mathrm{wt} . \%$ a uniform dispersion of copper sites over HAp surface was formed. In case of higher Cu loading (above $5 \mathrm{wt} . \%$ ) metal surface area is found to decrease, while the average particle size is increased due to $\mathrm{Cu}$ aggregation. These findings 
conclude that copper oxide is highly dispersed at lower loadings on HAp support i.e., for the 2 and 5 wt. $\%$ Cu catalysts. These results are well matched with XRD patterns.

The UV-visible spectroscopic analysis was carried out for various CuHAp catalysts and the results are shown in Figure 3. The characteristic charge transfer bands depict an idea of environment in the proximity of $\mathrm{Cu}^{2+}$ ions [43]. The spectra exhibited a maximum peak at $255 \mathrm{~nm}$, which is related to charge transfer transition between ligand to metal, i.e., $\mathrm{Cu}^{2+}$ ion and oxygen in a mononuclear species located at the surface. The blue shift was observed from $255 \mathrm{~nm}$ to $330 \mathrm{~nm}$ with copper loadings (2-20 wt.\%) over the HAp surface and this resulted in the aggregation of isolated copper particles and crystal growth of the linear sized copper oxide species. Thus, the axial $\mathrm{Cu}^{2+}-\mathrm{O}^{2-}$ bonds grow weaker while the in-plane $\mathrm{Cu}^{2+}-\mathrm{O}^{2-}$ bonds form stronger [44]. In addition to the charge transfer, a shoulder peak at $370 \mathrm{~nm}$ was found for 2 and $5 \mathrm{wt}$.\% copper loadings, which indicates that the formation of a highly dispersed and homogeneous $\mathrm{Cu}$ clusters was observed. According to the literature, at higher copper loadings a band at 350-450 $\mathrm{nm}$ was exhibited in the UV-DRS spectra, which was attribute to three-dimensional $\mathrm{Cu}^{+}$clusters in the $\mathrm{CuO}$ matrix [45]. At 650-750 nm, a low intense peak corresponds to the $\mathrm{d}-\mathrm{d}$ transitions of $\mathrm{Cu}^{2+}$ ions, which was situated in the octahedral geometry surrounded by $\mathrm{OH}$ symmetry.

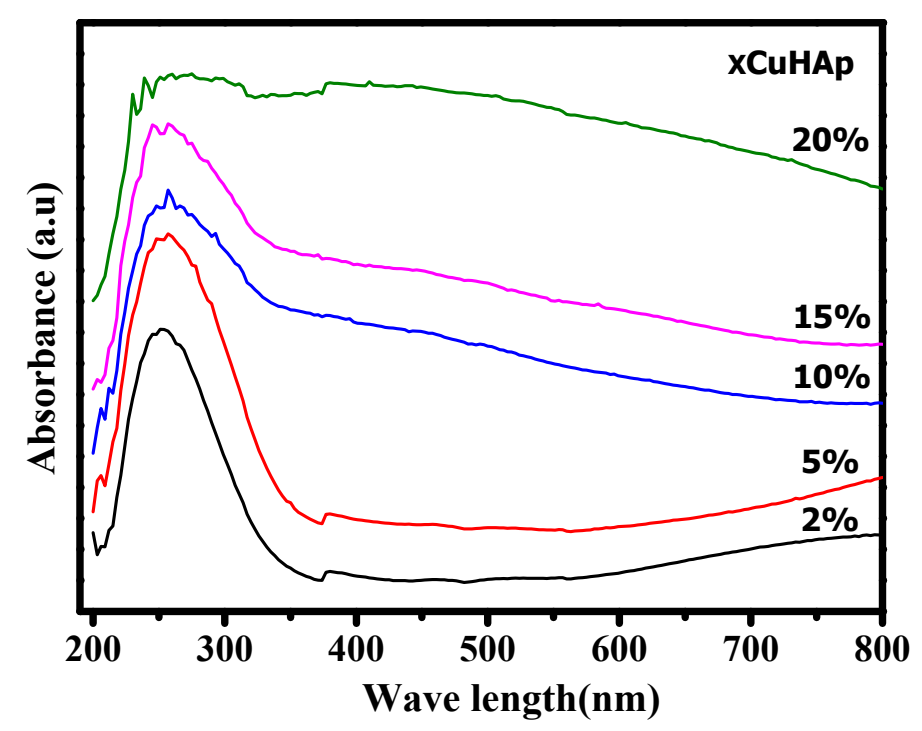

Figure 3. UVDRS spectra of CuHAp catalysts with different $\mathrm{Cu}$ loadings.

The TPR experiments were carried out to evaluate the reducibility of copper species in CuHAp catalysts and the profiles are shown in Figure 4. A significant change in the reduction peaks were noticed with different copper loadings along with bulk and surface copper oxides reduction occurred at different temperatures. At relatively low $\mathrm{Cu}$ content i.e., below $10 \mathrm{wt} . \%$, low temperature region was found to have two overlapping reduction peaks [46]. Highly dispersed $\mathrm{CuO}$ particles were presented in the 2CuHAp and 5CuHAp samples, which are reduced easily at low temperature region [47]. Furthermore, at higher copper loadings, i.e., $\geq 10 \mathrm{wt} . \%$, more than three peaks were observed related to higher temperature reduction of bulk copper species (above $300^{\circ} \mathrm{C}$ ). In the case of $10 \mathrm{CuHAp}$ catalyst, the reduction profile resulted in four peaks, in which three peaks are between 180 to $400{ }^{\circ} \mathrm{C}$ and a small peak found at $450-600{ }^{\circ} \mathrm{C}$. With the increase in $\mathrm{Cu}$ loading from $10 \mathrm{wt} . \%$ to $20 \mathrm{wt} . \%$, a peak was observed towards higher temperature region at $270{ }^{\circ} \mathrm{C}$. Moreover, combination of small peak at 300-320 ${ }^{\circ} \mathrm{C}$ was also appeared. The peak broadening and the shifting of the $\mathrm{T}_{\max }$ towards the high temperature region was observed for the higher $\mathrm{Cu}$ loadings, which could be due to the increased crystallinity of $\mathrm{CuO}$. Herein, the shoulder peak represents the two-step reduction process of bulk $\mathrm{CuO}$ species. From literature, the reduction process of bulk $\mathrm{CuO}$ to metallic $\mathrm{Cu}$ take place via $\mathrm{Cu}^{2+}$ to $\mathrm{Cu}^{1+}$ and $\mathrm{Cu}^{1+}$ to $\mathrm{Cu}^{0}$. The peak position between 350 and $400{ }^{\circ} \mathrm{C}$ was corresponding to the reduction of 
$\mathrm{Cu}^{2+}$ ions $(\mathrm{CuO})$ in $\mathrm{Cu}_{2}(\mathrm{OH})\left(\mathrm{PO}_{4}\right)$ matrix, which is a new solid phase-libethenite [41]. The fourth peak could be the result of surface carbonates reduction between 450 and $600{ }^{\circ} \mathrm{C}$.

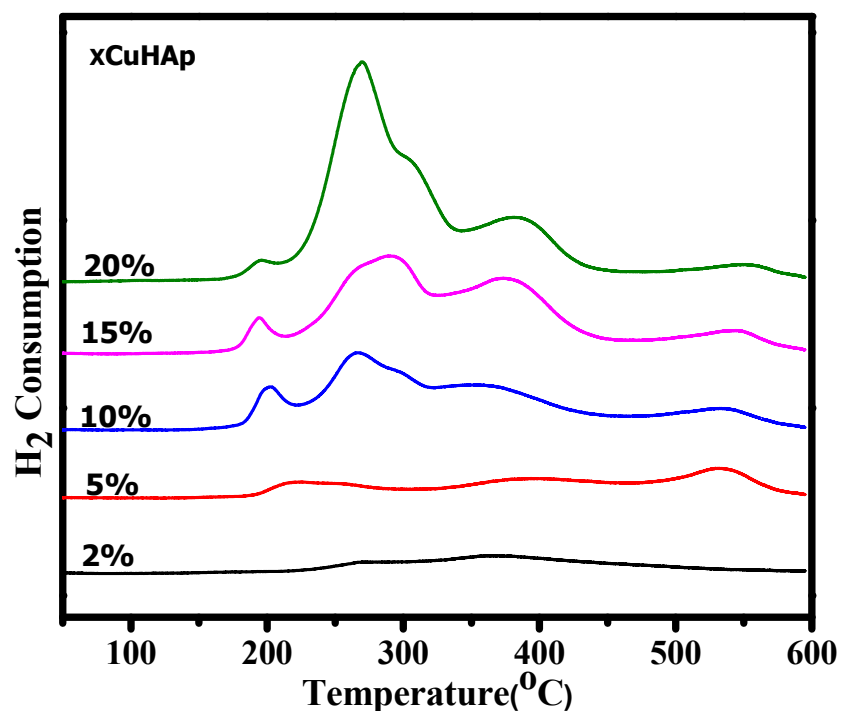

Figure 4. TPR profiles of CuHAp catalysts with various $\mathrm{Cu}$ loadings.

The basicity type and strength of various $\mathrm{Cu}$-supported HAp samples were measured by $\mathrm{CO}_{2}$-TPD and the $\mathrm{CO}_{2}$ desorbed profiles are displayed in Figure 5. In general, the basicity of metal oxide is of three types (weak, medium and strong) [44]. In Figure 5, the TPD profiles had three desorption peaks for all the studied catalysts in the region of $50-200{ }^{\circ} \mathrm{C}, 200-500{ }^{\circ} \mathrm{C}$ and $500-650{ }^{\circ} \mathrm{C}$, which are assigned as weak, medium and strong basic sites, respectively. The surface -OH groups are associated with the weak basic sites, the medium basic sites are related to metal-oxygen pairs and the low-coordination oxygen anions are ascribed to the strong basic sites [48]. 2CuHAp and 5CuHAp samples show similar trend but the intensities differ; later one exhibited more intense peaks than the former one. With the increase in Cu loading from $5 \mathrm{wt} . \%$ to $20 \mathrm{wt} . \%$, the intensities of the three peaks are gradually decreased due to the surface coverage of bulk $\mathrm{CuO}$ phase. Interestingly, the appearance of new peak for 10CuHAp, 15CuHAp and 20CuHAp samples in the region of 500-650 ${ }^{\circ} \mathrm{C}$ might be due to desorption of $\mathrm{CO}_{2}$ from $\mathrm{CuCO}_{3}$ [49]. Moreover, the $\mathrm{T}_{\max }$ of new peak is shifted to lower temperature region. Finally, TPD- $\mathrm{CO}_{2}$ results revealed that the $5 \mathrm{CuHAp}$ sample possess maximum number of surface basic sites compared to all investigated samples.

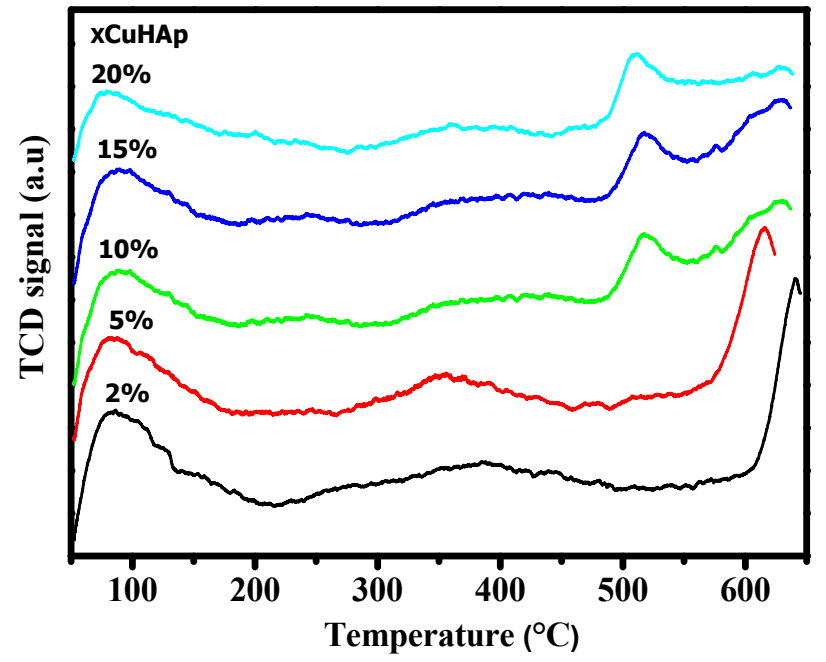

Figure 5. $\mathrm{CO}_{2}-\mathrm{TPD}$ profiles of $\mathrm{CuHAp}$ catalysts with different $\mathrm{Cu}$ loadings. 
The morphology of the pure HAp- and Cu-modified HAp catalytic materials were analysed using scanning electron microscopy (SEM-EDS) and transmission electron microscopy (TEM). SEM image and corresponding EDX-mapping of 5CuHAp (Figure 6) show the distribution of $\mathrm{Ca}, \mathrm{Cu}, \mathrm{O}$ and $\mathrm{P}$ atoms are presented in the $\mathrm{Cu}$-modified HAp support. The EDX analysis attached to electron microscope revealed that the $\mathrm{Cu}$ content of 5CuHAP sample is $4.2 \mathrm{wt} . \%$, which was almost similar to the value determined by ICP and $\mathrm{Ca} / \mathrm{P}$ ratio was found to be 1.54 . The TEM image of HAp (Figure 7) indicated that the mixed oxide phase and hybrid structure with nanorods were seen and have lateral sizes ranging from $50 \mathrm{~nm}$ to $200 \mathrm{~nm}$.

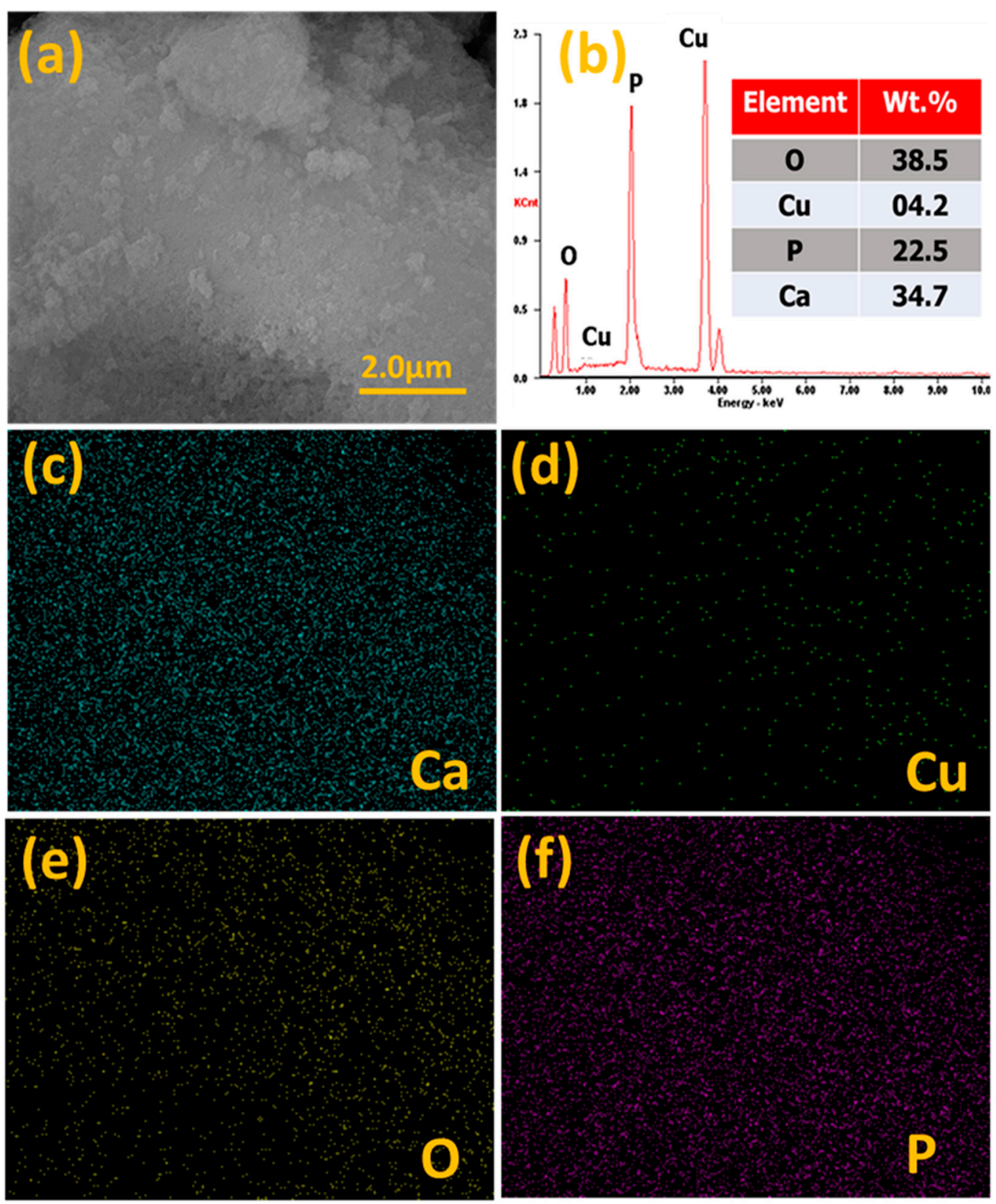

Figure 6. (a) SEM image, (b) EDS results and (c-f) are corresponding EDS elemental mapping images of 5CuHAp catalyst. 

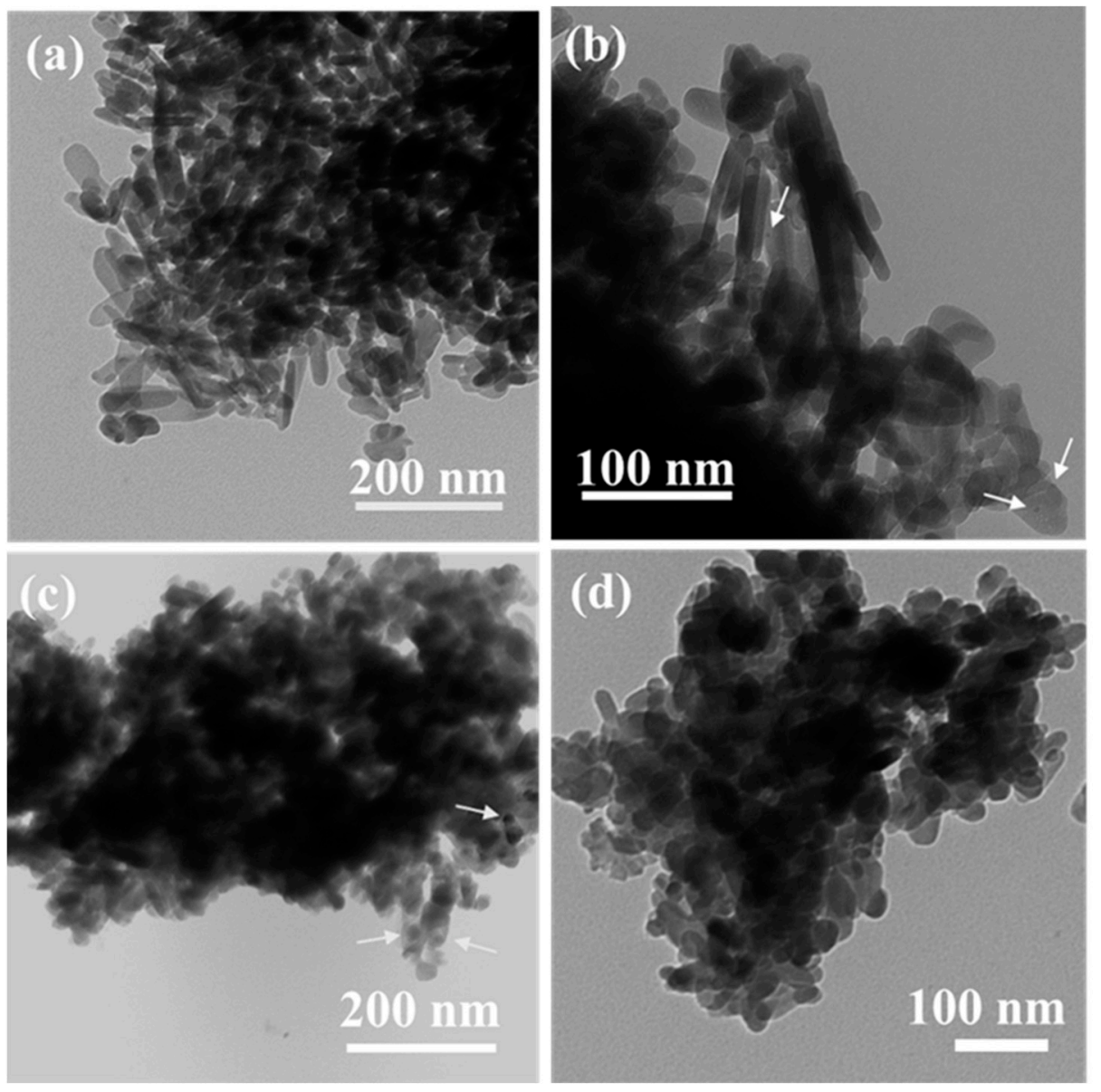

Figure 7. TEM images of (a) HAp, (b) 5 CuHAp (c) 20 CuHAp and (d) Spent 5Cu/HAp catalysts.

\subsection{Catalytic Activity}

The liquid phase conversion of FA to FAOL was carried out by using 2-propanol as the H-donor for the prepared catalysts. The solubility of 2-propanol with FA was found to be better for the liquid phase catalytic transformation of FA. He et al. reported that highest FA conversion and FAOL selectivity was achieved by using 2-propanol as the $\mathrm{H}$ donor when compared to other solvents such as ethanol, 1-butanol, 2-butanol, tert-butanol and n-propanol [22].

\subsubsection{Effect of $\mathrm{Cu}$ Loading on $\mathrm{CTH}$ of FA}

The effect of copper loading on the catalytic transfer hydrogenation of FA to FAOL was investigated and the results are presented in Figure 8. Initially, pure HAp support was tested in the FA hydrogenation at $140{ }^{\circ} \mathrm{C}$ and exhibited relatively low FA conversion of $6 \%$ and moderately FAOL selectivity of $61 \%$ was attained. Copper modified HAp catalysts were tested and found to be complete selective to FAOL and exhibited different conversion values based on the copper loading (2-20 wt.\%). Thus, enhanced activity in FA conversion and FAOL selectivity was achieved because of the introduction of copper. However, the FA conversion varies between 56 and $96 \%$ with the $\mathrm{Cu}$ loadings which had significant role in the final activity of the catalysts. Highest conversion of FA was obtained over 5CuHAp catalyst and thereafter, the conversion declined with copper loading. Fan et al. reported that the basic $\gamma-\mathrm{Fe}_{2} \mathrm{O}_{3} @ \mathrm{HAP}$ catalyst exhibited $96.2 \%$ of FA conversion at $180{ }^{\circ} \mathrm{C}$ in $10 \mathrm{~h}$ reaction time [31]. Chen et al. reported that $\mathrm{Cu} / \mathrm{MgO}-\mathrm{Al}_{2} \mathrm{O}_{3}$ catalyst shows complete conversion of $\mathrm{FA}$ and $89.3 \%$ of FAOL selectivity at $210{ }^{\circ} \mathrm{C}$ in $1 \mathrm{~h}$ reaction time [50]. In this work, we found that 5CuHAp catalyst exhibited highest conversion of FA (96\%) and selectivity $(100 \%)$ to FAOL at $140{ }^{\circ} \mathrm{C}$ in $4 \mathrm{~h}$ reaction time. 


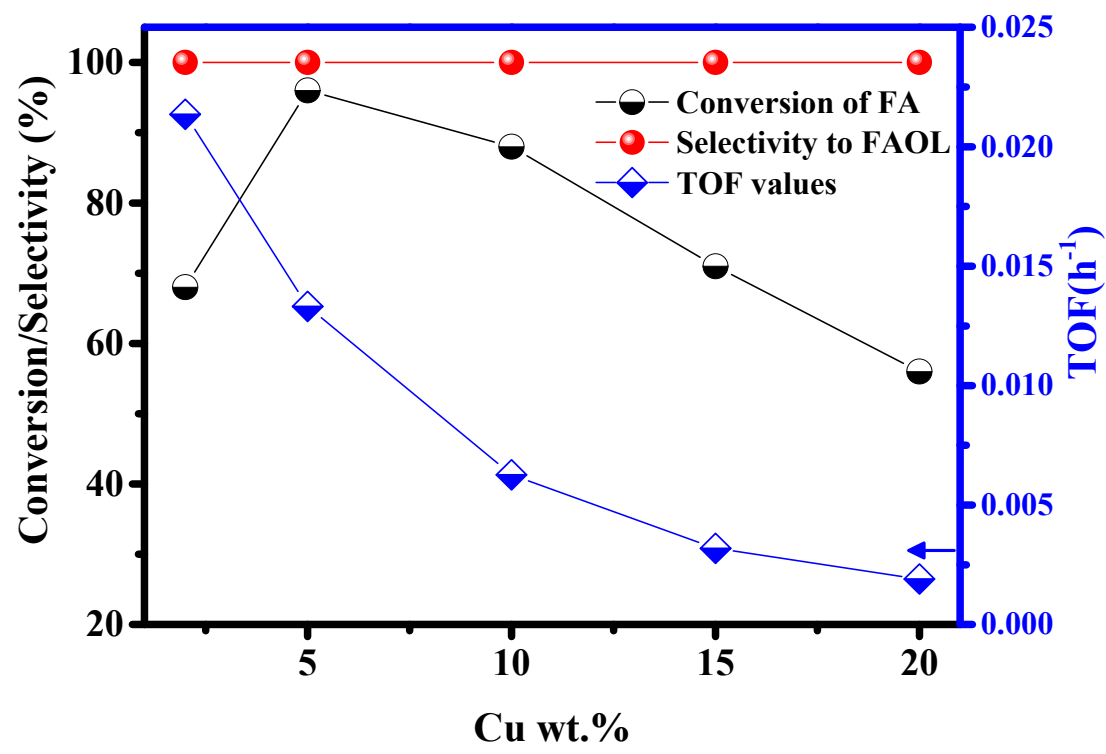

Figure 8. The effect of copper loadings (2-20 wt.\%) on the CTH of FA to FAOL and corresponding TOF values are presented. Reaction Conditions: The catalyst amount (100 mg), 2-propanol (5 mL), FA (480 mg), reaction temperature $-140{ }^{\circ} \mathrm{C}$ at $2 \mathrm{MPa}$ N2 pressure and reaction time $-4 \mathrm{~h}$.

The catalytic activity results are well correlated with the physico-chemical properties of the catalysts which are obtained by using different characterisation techniques. From XRD results, increasing the loadings above $5 \mathrm{wt}$.\% $\mathrm{Cu}$ leads to aggregation of $\mathrm{Cu}$ on the surface of HAp. UVDRS analysis also suggests that the successful impregnation of $\mathrm{Cu}$-ion into HAp structure at the same time was found to be increasing the crystallinity at higher loadings. In addition, over 5 wt. $\% \mathrm{Cu}$ catalyst, $\mathrm{N}_{2} \mathrm{O}$ and TPD- $\mathrm{CO}_{2}$ results demonstrated that 5CuHAp owned maximum number of basic sites and copper active surface area compared to all the investigated catalysts. The plot between turn over frequency (TOF) versus $\mathrm{Cu}$ loading describes the relation between catalytic activity and the Cu loading (Figure 9), wherein the TOF is proportional to the rate of FA molecules converted per second per site of copper. TOF is much higher for the 2CuHAp catalyst could be due to existence of isolated copper ions in the sample. The similar observation was also reported by Chary et al. in the case of $\mathrm{Cu}-\mathrm{Al}_{2} \mathrm{O}_{3}$ catalysts [51]. TOF values were gradually declined with copper loading and obtained higher TOF values at lower Cu loading.

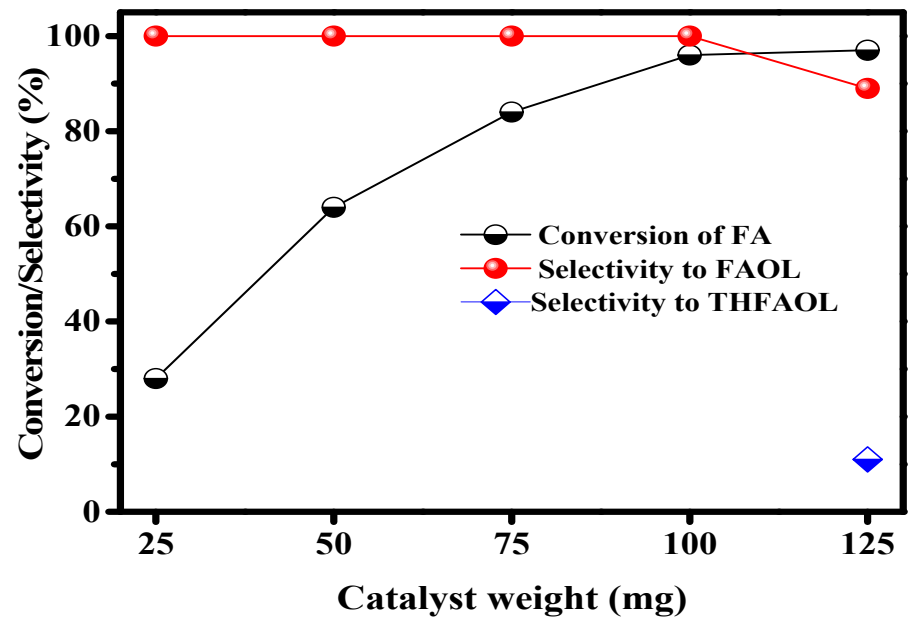

Figure 9. The effect of catalyst weight (mg) on the CTH of FA over 5CuHAp catalyst. Reaction conditions: catalyst amount (25-125 mg), 2-propanol (5 mL), FF (480 mg), reaction temperature-140 ${ }^{\circ} \mathrm{C}$ at $2 \mathrm{MPa} \mathrm{N}_{2}$ pressure and reaction time- $-4 \mathrm{~h}$. 


\subsubsection{Effect of Catalyst Weight on CTH of FA}

To evaluate the catalyst effectiveness in the hydrogen transfer during FA conversion to FAOL, the amount of catalyst was varied from 25 to $125 \mathrm{mg}$. FA conversion is increased with the catalyst mass from 25 to $125 \mathrm{mg}$ (Figure 9). The selectivity remained constant until $100 \mathrm{mg}$ and thereafter, slightly declined at $125 \mathrm{mg}$ of catalyst. As the catalyst amount increased from 25 to $100 \mathrm{mg}$, the FA conversion increased from $28 \%$ to $96 \%$ while the selectivity towards FAOL was constant at $100 \%$. Henceforth, $100 \mathrm{mg}$ catalyst loading was selected as the optimal weight for the better performance and chosen for the further catalytic activity tests.

\subsubsection{Effect of $\mathrm{N}_{2}$ Pressure on $\mathrm{CTH}$ of FA}

The effect of reaction pressure on the catalytic activity was evaluated for 5CuHAp catalyst. Figure 5 represents the influence of reaction pressure on the catalytic performances. It was found that the reaction pressure had significant influence on FA conversion and selectivity. From Figure 10, conversion and selectivity increased with the reaction pressure up to $2 \mathrm{MPa}$ and the values are almost similar at $3 \mathrm{MPa}$ as well. Above $3 \mathrm{MPa}$, the selectivity slightly declined caused by the formation tetrahydro furfuryl alcohol (THFAOL). Finally, $2 \mathrm{MPa}$ was found to be the most optimised pressure where the highest performance can be achieved.

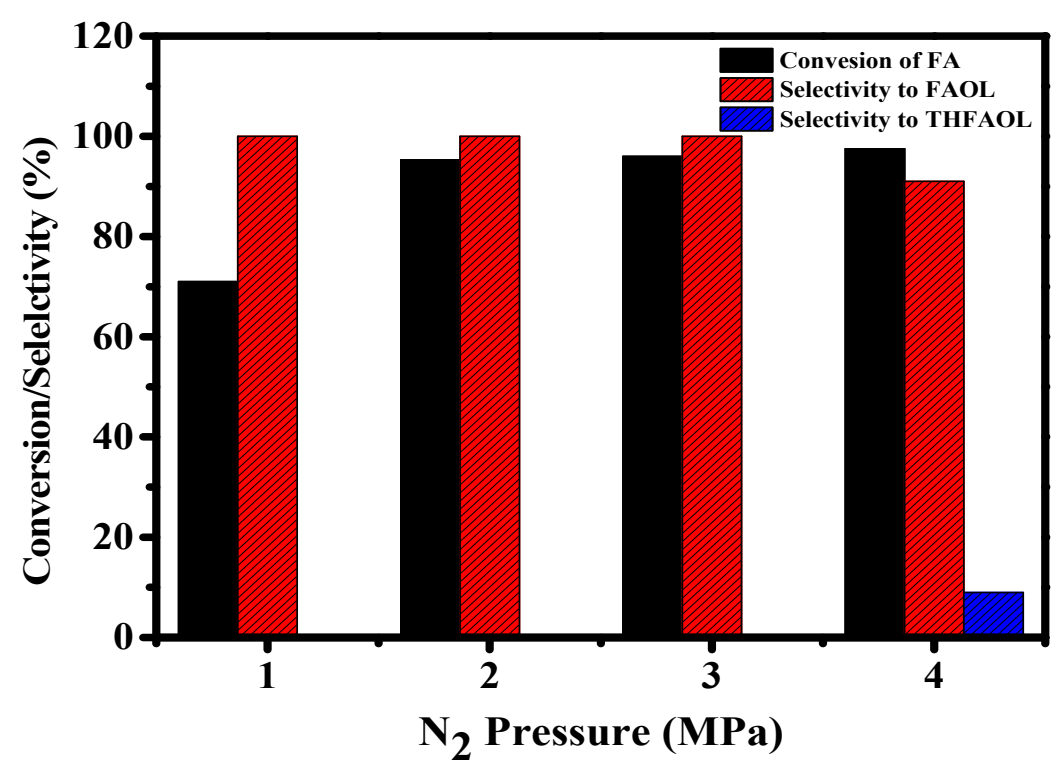

Figure 10. The effect of $\mathrm{N}_{2}$ pressure on the CTH of FA over 5CuHAp. Reaction Conditions: The catalyst amount (100 mg), 2-propanol (5 mL), FF (480 mg), reaction temperature-140 ${ }^{\circ} \mathrm{C}$ at (1-4) $\mathrm{MPa} \mathrm{N}_{2}$ pressure and reaction time $-4 \mathrm{~h}$.

\subsubsection{Effect of Reaction Temperature on CTH of FA}

The effect of temperature on CTH of FA to FAOL with 5CuHAp catalyst was investigated with temperature between 110 and $150{ }^{\circ} \mathrm{C}$ and at reaction time of $4 \mathrm{~h}$, with $100 \mathrm{mg}$ of catalyst (Figure 11). The reaction temperature was one of the key parameters in the catalytic hydrogen transfer of FA to FAOL. As shown in Figure 11, within $4 \mathrm{~h}$ of reaction at $110{ }^{\circ} \mathrm{C}$, the conversion of furfural was only $24 \%$. When the reaction temperature increased from 110 to $150{ }^{\circ} \mathrm{C}$, the FA conversion increased from $24 \%$ to $98 \%$ but the reaction is highly selective towards FAOL. However, the FAOL selectivity was independent of temperature, at $150{ }^{\circ} \mathrm{C}$ the reaction was accompanied with the formation of small amount of THFAOL as confirmed from GC-MS spectra, suggesting the high selectivity performance of 5CuHAp catalyst. 


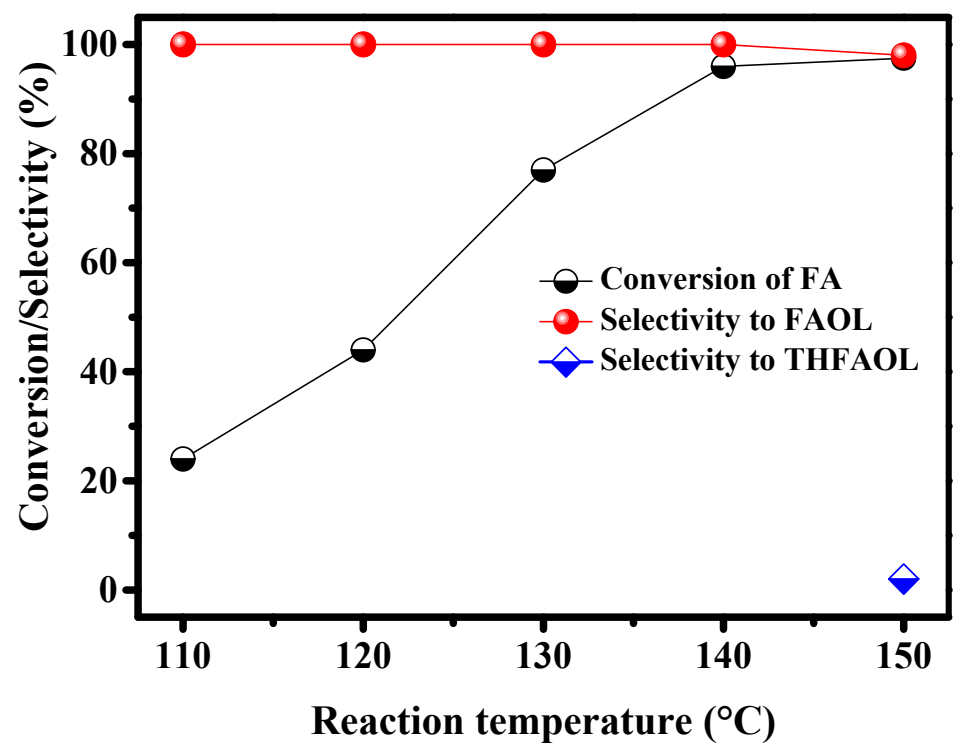

Figure 11. The effect of reaction temperature on the CTH of FA over 5CuHAp. Reaction Conditions: The catalyst weight $(100 \mathrm{mg}), 2$-propanol $(5 \mathrm{~mL}), \mathrm{FF}(480 \mathrm{mg})$, reaction temperature- $\left(110-150{ }^{\circ} \mathrm{C}\right)$ at $2 \mathrm{MPa} \mathrm{N}_{2}$ pressure and reaction time $-4 \mathrm{~h}$.

\subsubsection{Effect of Reaction Time on CTH of FA}

The effect of reaction time over 5CuHAp catalyst was investigated on the FA conversion and product selectivity. As shown in Figure 12, the conversion of FA increased upon increasing the reaction time. More specifically, after $3 \mathrm{~h}$, conversion of $85 \%$ was achieved, which increased steadily to $96 \%$ after $4 \mathrm{~h}$. The selectivity of FAOL was maximum from starting time to $4 \mathrm{~h}$ reaction time. However, at extended time to $5 \mathrm{~h}$ there is a slight decline in the selectivity of FAOL and very small amount of THFAOL formed.

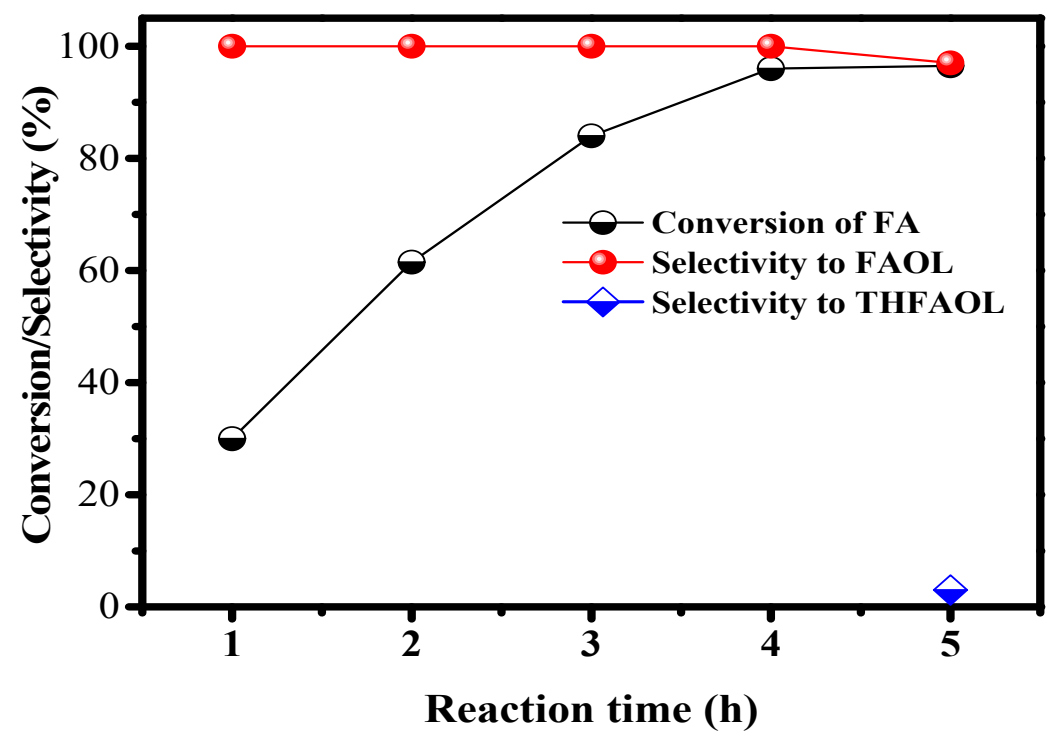

Figure 12. The effect of reaction time on the CTH of FA over 5CuHAp. Reaction Conditions: The catalyst amount $(100 \mathrm{mg}), 2$-propanol $(5 \mathrm{~mL}), \mathrm{FF}(480 \mathrm{mg})$, reaction temperature- $140{ }^{\circ} \mathrm{C}$ at $2 \mathrm{MPa} \mathrm{N}_{2}$ pressure and reaction time- $-(1-5 \mathrm{~h})$. 


\subsubsection{Recyclibity of 5CuHAp}

To examine the stability of the catalysts we carried out recyclability experiments for 5CuHAp catalyst under optimised conditions. In each cycle, the catalyst was removed from the reaction mixture by simple centrifugation, and washed with ethanol before drying at $60{ }^{\circ} \mathrm{C}$ under vacuum for $6 \mathrm{~h}$. After drying, the catalyst was tested for the reproducibility of the results in similar conditions (Figure 13). The regeneration and reproducibility of the results were repeated in five successive cycles. From Figure 13, a slight drop in the FA conversion from cycle 1 to cycle 5 was noticed, while the selectivity to furfuryl alcohol remained constant. The decline in conversion is mainly due to the catalyst deactivation occurred through surface oxidation of metallic copper during recycling process. This phenomenon was confirmed by carrying out additional test with spent catalyst recycling. After five cycles, spent catalyst was re-calcined and reduced in $5 \% \mathrm{H}_{2} / \mathrm{Ar}$ flow and tested for CTH of FA. The tested catalyst achieved $91 \%$ conversion of FA and 100\% selectivity to FAOL and regeneration of the initial catalyst activity was gained. The morphology of the spent 5CuHAp catalyst is shown in Figure 7 and significant HAp rods accumulation can be noticed. The catalytic performance for the CTH reaction of FA to FAOL over CuHAp is compared in Table 2 with different copper catalysts reported in recent literature.

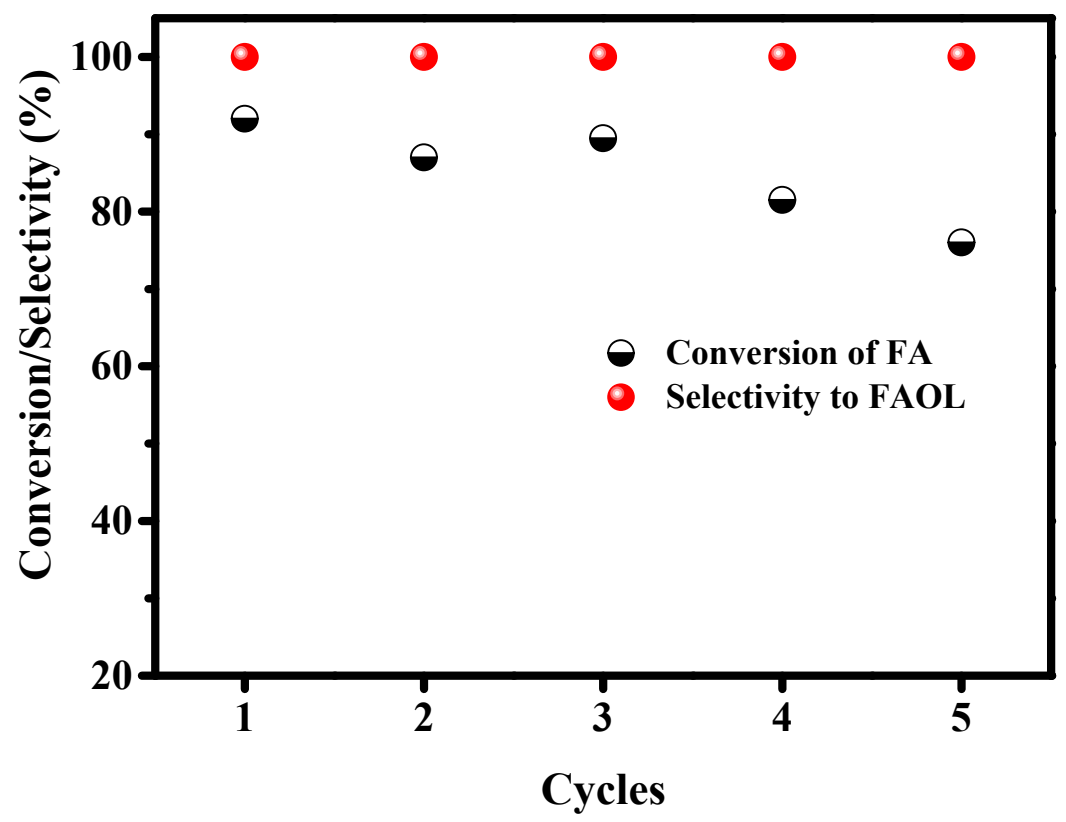

Figure 13. Recyclability test for 5CuHAp catalyst. Reaction Conditions: The catalyst amount (100 mg), 2-propanol (5 mL), FF (480 mg), reaction temperature- $140{ }^{\circ} \mathrm{C}$ at $2 \mathrm{MPa} \mathrm{N}_{2}$ pressure and reaction time-(4h).

Table 2. Comparison of the catalytic activity of $\mathrm{Cu}$-based catalysts with various copper loadings published in the literature on CTH of FA to FAOL reaction.

\begin{tabular}{cccccccc}
\hline Catalyst & H-Donor & $\mathbf{T}\left({ }^{\circ} \mathbf{C}\right)$ & $\mathbf{P}(\mathbf{M P a})$ & Time (h) & $\mathbf{X}_{\text {FA }}(\mathbf{\%})$ & $\mathbf{S}_{\text {FAOL }}(\mathbf{\%})$ & Ref. \\
\hline $\mathrm{Cu} / \mathrm{AC}-\mathrm{SO}_{3} \mathrm{H}$ & $2-\mathrm{PrOH}$ & 150 & 4 & 5 & 100 & 100 & {$[52]$} \\
$\mathrm{Cu}-\mathrm{Al}$ & $\mathrm{MeOH}$ & 200 & 1 & 2.5 & 100 & 94 & {$[35]$} \\
$\mathrm{Cu}-\mathrm{Mg}-\mathrm{Al}$ & $2-\mathrm{PrOH}$ & 150 & - & 6 & 100 & 100 & {$[21]$} \\
$\mathrm{Cu}-\mathrm{Mg}-\mathrm{Al}_{2} \mathrm{O}_{3}$ & $2-\mathrm{PrOH}$ & 210 & - & 1 & 100 & 89.3 & {$[50]$} \\
$\mathrm{CuCs}-\mathrm{MCM}$ & $\mathrm{HCOOH}$ & 170 & - & 1 & 100 & 99.6 & {$[53]$} \\
$\mathrm{CuHAp}$ & 2-PrOH & 140 & 2 & 4 & 96 & 100 & This work \\
\hline \multicolumn{7}{c}{ 2-PrOH = 2-propanol, MeOH = methanol, X-conversion, S-selectivity. }
\end{tabular}




\section{Materials and Methods}

\subsection{Synthesis of Catalysts}

The double decomposition method was used to synthesise calcium hydroxyapatite. The synthesis procedure is as follows: a mixture of ammonium hydrogen phosphate solution (Sinopharm Chemical Reagent Co., Ltd., Shanghai, China) (0.4 M) with calcium nitrate solution (Sinopharm Chemical Reagent Co., Ltd., China) (0.5 M) was prepared in the presence of ammonia. The mixture of ammonium hydrogen phosphate (Sinopharm Chemical Reagent Co., Ltd., China) (7.92 gm in $100 \mathrm{~mL}$ ) and ammonia (Kermel Reagents Co., Ltd., Tianjing, China) $(70 \mathrm{~mL})$ is added dropwise to the boiling calcium nitrate solution $\left(23.6 \mathrm{gm}\right.$ in $100 \mathrm{~mL}$ ). The resulting mixture was further heated under reflux for $3 \mathrm{~h}$ at $80^{\circ} \mathrm{C}$ and filtered in warm condition. The recovered precipitate solids were washed thoroughly with ultrapure hot water to eliminate the traces of nitrates before drying at $110^{\circ} \mathrm{C}$ for $24 \mathrm{~h}$. Finally, the dried solids were calcined at $400{ }^{\circ} \mathrm{C}$ for $2 \mathrm{~h}$ in ambient air atmosphere.

Copper catalysts with varying copper loadings (from 2.0 to $20.0 \mathrm{wt} . \%$ ) were prepared on HAp supports by wet chemical impregnation method using aqueous copper nitrate solution. The prepared samples were dried at $110{ }^{\circ} \mathrm{C}$ in oven for $12 \mathrm{~h}$ and before calcining at $500{ }^{\circ} \mathrm{C}$ for $5 \mathrm{~h}$ in air atmosphere. All the catalysts are named as $\mathrm{xCuHAp}$, where $(\mathrm{x})$ represents the $\mathrm{Cu}$ loadings $(\%)$.

\subsection{Activity Tests}

CTH of FA was carried out in a stainless-steel autoclave reactor $(10 \mathrm{~mL})$ with an inserted glass liner. Reaction temperature was insured with an oil bath on a digital hotplate by a thermocouple. In a typical CTH experiment, the catalyst $(100 \mathrm{mg})$, isopropanol as the solvent $(5 \mathrm{~mL})$, reactant FA (480 mg) and decane ( $50 \mu \mathrm{L}$, internal standard for GC) were initially introduced into the reactor. Subsequently, the reaction autoclave was purged with $\mathrm{H}_{2}$ gas. Prior to the activity tests, catalysts were activated ex situ in $5 \% \mathrm{H}_{2} / \mathrm{Ar}$ flow $(30 \mathrm{~mL} / \mathrm{min})$ at $350{ }^{\circ} \mathrm{C}$ for $2 \mathrm{~h}$ and then transferred to the reactor, under to an initial value of $2 \mathrm{MPa}$ measured at room temperature. Further, the reactor was heated to the desired reaction temperature under a stirring rate of $700 \mathrm{rpm}$. The reaction products were analysed by a gas chromatograph (GC, Agilent, DB-WAX column) and further liquid by-products were analysed by GC-MS column (Agilent DB-WAX). To study the recyclability of the catalyst, at the end of hydrogenation run, the catalyst was removed from the reaction mixture by centrifugation and washed with ethanol before drying at $60^{\circ} \mathrm{C}$ under vacuum for $6 \mathrm{~h}$. The FA conversion is defined as the moles of FA reacted divided by the moles of initial introduced FA; similarly, the selectivity of FAOL is defined as the moles of FAOL produced divided by the moles of FA reacted; and the yield of FAOL is defined as the moles of FAOL produced divided by the moles of initial introduced FA.

\subsection{Catalytic Characterisation}

The synthesised catalysts were characterised to understand the structural and chemical properties such as basicity, surface area and morphology by using temperature programmed desorption (TPD), $\mathrm{N}_{2}$ sorption, scanning electron microscopy (SEM), X-ray diffraction (XRD) and FTIR techniques. XRD was performed using an Ultima IV diffractometer (Rigaku Corporation, Japan) with a Ni-filtered $\mathrm{Cu} \mathrm{K} \alpha$ radiation $(\lambda=1.5406 \AA)$ operated at $40 \mathrm{kV}$ and $30 \mathrm{~mA}$. The FT-IR spectra were recorded at room temperature on a spectrometer (Bruker TENSOR 27) in the range of $400-3500 \mathrm{~cm}^{-1}$. The specific surface areas were measured by $\mathrm{N}_{2}$ sorption at $-196{ }^{\circ} \mathrm{C}$ temperature in Autosorb-1C instrument (Quanta chrome instruments, USA). The morphological features of the samples were obtained by SEM (Model: EVO 18, Carl Zeiss) instrument. TEM images were captured on Hitachi HT7700 operated at $100 \mathrm{kV}$. The copper content was determined by elemental analysis by using ICP-OES (M/s Thermo Scientific, iCAP6500 DU). Temperature-programmed reduction (TPR) studies were carried out on AutoChem 2910 (Micromeritics, Norcross, GA, USA) instrument. In TPR experiment, $100 \mathrm{mg}$ of oven-dried catalyst sample was taken in a U-shaped quartz sample tube. The catalyst was mounted on top of a quartz wool plug. Before the TPR experiments, the catalyst sample was pretreated at $200{ }^{\circ} \mathrm{C}$ 
for $2 \mathrm{~h}$ under He flow. After pretreatment the sample was cooled to ambient temperature and TPR analysis was carried out in a flow of $5 \% \mathrm{H}_{2}$-Ar from ambient temperature to $600{ }^{\circ} \mathrm{C}$ at a ramping rate of $10^{\circ} \mathrm{C} / \mathrm{min}$. The surface basicity of catalyst samples was determined by using TPD (M/s Micromeritics, AutoChem 2910 instrument USA) and $\mathrm{CO}_{2}$ as a probe molecule in basicity experiments. In a typical experiment, $\sim 50 \mathrm{mg}$ of sample was loaded in a U-shaped quartz tube and pre-treated at $300{ }^{\circ} \mathrm{C}$ for $1 \mathrm{~h}$ in the flow of pure He. Thereafter, pre-treated sample was saturated with $\mathrm{CO}_{2}$ at $30^{\circ} \mathrm{C}$ for $30 \mathrm{~min}$. The physiosorbed $\mathrm{CO}_{2}$ was removed by treating the sample at $100^{\circ} \mathrm{C}$ for $30 \mathrm{~min}$ in He flow. Finally, the amount of desorbed $\mathrm{CO}_{2}$ was estimated using TCD detector by heating the sample from $50-700{ }^{\circ} \mathrm{C}$ at a ramping rate of $10^{\circ} \mathrm{C} / \mathrm{min}$. $\mathrm{N}_{2} \mathrm{O}$ decomposition experiments were also conducted on micrometric instruments (Auto Chem. 2910). Prior to analysis, the sample was reduced with $\mathrm{H}_{2}$ gas at $350{ }^{\circ} \mathrm{C}$ for 2 $\mathrm{h}$ followed by He purges for $30 \mathrm{~min}$ and then cooled to $80^{\circ} \mathrm{C}$. Thereafter, sample was exposed to $2 \%$ $\mathrm{N}_{2} \mathrm{O}-\mathrm{He}$ for $30 \mathrm{~min}$ to oxidise $\mathrm{Cu}$ to $\mathrm{Cu}_{2} \mathrm{O}$. Reduction of surface copper oxide species was performed by the similar procedure as TPR. Moreover, $\mathrm{Cu}$ surface area, dispersion and crystal size were evaluated from the total amount of $\mathrm{H}_{2}$ consumed during the TPR analysis and by $\mathrm{N}_{2} \mathrm{O}$ decomposition method.

\section{Conclusions}

In this work, we designed and developed inexpensive and environmentally benign Cu-modified hydroxyapatite (HAp) catalyst for $\mathrm{CTH}$ of furfural to furfural alcohol using iso-propanol as an internal $\mathrm{H}_{2}$ source. The $\mathrm{Cu}$ loading was found to have profound effect on the reaction performance. The X-ray diffraction patterns confirmed larger crystallites were formed with increasing copper loadings. Copper with $5 \mathrm{wt}$ \% over HAp was the most optimal loading to exhibit desired catalytic properties. Systematic characterisation results revealed that over 5CuHAp catalyst, highly dispersed copper particles and high surface basicity was obtained. Complete selectivity and $96 \%$ conversion with high TOF values were achieved over the 5CuHAp catalyst. Moreover, optimised reaction conditions such as temperature, pressure and catalyst weight were determined. The stability of the catalysts was also studied with regeneration and reusability tests and scope to develop further to gain high catalyst durability for the commercial application. Henceforth, 5CuHAp catalyst is promising and shows better performance compared to other $\mathrm{Cu}$-based catalysts published in the literature at relatively lower temperature.

Author Contributions: B.P. (conceptualisation) (writing—original draft) (software), P.K.S. (writing introduction, data analysis and curation) (methodology), G.S. (investigation), K.R. (software) R.R. (validation), K.R.R. (writing-review and editing), T.L. (supervision). All authors have read and agreed to the published version of the manuscript.

Funding: This research was funded by National Natural Science Foundation of China (Project No.51871114).

Acknowledgments: We gratefully acknowledge the financial support from National Natural Science Foundation of China.

Conflicts of Interest: The authors declare no conflict of interest.

\section{References}

1. Beims, R.F.; Hu, Y.; Shui, H.; Xu, C.C. Hydrothermal liquefaction of biomass to fuels and value-added chemicals: Products applications and challenges to develop large-scale operations. Biomass Bioenerg. 2020, 135, 105510. [CrossRef]

2. Kucherov, F.A.; Romashov, L.V.; Galkin, K.I.; Ananikov, V.P. Chemical Transformations of Biomass-Derived C6-Furanic Platform Chemicals for Sustainable Energy Research, Materials Science, and Synthetic Building Blocks. ACS Sustain. Chem. Eng. 2018, 6, 8064-8092. [CrossRef]

3. Wang, M.; Dewil, R.; Maniatis, K.; Wheeldon, J.; Tan, T.; Baeyens, J.; Fang, Y. Biomass-derived aviation fuels: Challenges and perspective. Prog. Energy Combust. Sci. 2019, 74, 31-49. [CrossRef]

4. Audemar, M.; Wang, Y.; Zhao, D.; Royer, S.; Jérôme, F.; Len, C.; De Oliveira Vigier, K. Synthesis of Furfuryl Alcohol from Furfural: A Comparison between Batch and Continuous Flow Reactors. Energies 2020, 13, 1002. [CrossRef] 
5. Xu, C.; Paone, E.; Rodríguez-Padrón, D.; Luque, R.; Mauriello, F. Recent catalytic routes for the preparation and the upgrading of biomass derived furfural and 5-hydroxymethylfurfura. Chem. Soc. Rev. 2020, 49, 4273-4306. [CrossRef] [PubMed]

6. Wang, Y.; Zhao, D.; Rodríguez-Padrón, D.; Len, C. Recent Advances in Catalytic Hydrogenation of Furfural. Catalysts 2019, 9, 796. [CrossRef]

7. Zhang, Z.; Tong, X.; Zhang, H.; Li, Y. Versatile catalysis of iron: Tunable and selective transformation of biomass-derived furfural in aliphatic alcohol. Green Chem. 2018, 20, 3092-3100. [CrossRef]

8. Svetlana, A.S.; Andrey, A.S.; Alexander, V.F.; Olga, A.B.; Andrey, A.S.; Maksim, Y.L.; Vadim, A.Y. Highly Active $\mathrm{Cu}$ FeAl-containing Catalysts for Selective Hydrogenation of Furfural to Furfuryl Alcohol. Catalysts 2019, 9, 816.

9. Mariscal, R.; Maireles-Torres, P.; Ojeda, M.; Sádaba, I.; Granados, M.L. Furfural: A renewable and versatile platform molecule for the synthesis of chemicals and fuels. Energy Environ. Sci. 2016, 9, 1144-1189. [CrossRef]

10. Srivastava, S.; Jadeja, G.; Parikh, J.K. Copper-cobalt catalyzed liquid phase hydrogenation of furfural to 2-methylfuran: An optimization, kinetics and reaction mechanism study. Chem. Eng. Res. Des. 2018, 132, 313-324. [CrossRef]

11. Gallezot, P. Conversion of biomass to selected chemical products. Chem. Soc. Rev. 2012, 41, 1538-1558. [CrossRef] [PubMed]

12. Rasina, D.; Lombi, A.; Santoro, S.; Ferlin, F.; Vaccaro, L. Searching for novel reusable biomass-derived solvents: Furfuryl alcohol/water azeotrope as a medium for waste-minimised copper-catalysed azide-alkyne cycloaddition. Green Chem. 2016, 18, 6380-6386. [CrossRef]

13. Yan, K.; Wu, G.; LaFleur, T.; Jarvis, C. Production, properties and catalytic hydrogenation of furfural to fuel additives and value-added chemicals. Renew. Sustain. Energy Rev. 2014, 38, 663-676. [CrossRef]

14. Romano, P.N.; De Almeida, J.M.A.R.; Carvalho, Y.; Priecel, P.; Sousa-Aguiar, E.F.; Lopez-Sanchez, J.A. Microwave-Assisted Selective Hydrogenation of Furfural to Furfuryl Alcohol Employing a Green and Noble Metal-Free Copper Catalyst. ChemSusChem 2016, 9, 3387-3392. [CrossRef]

15. Rodiansono, R.; Astuti, M.D.; Mujiyanti, D.R.; Santoso, U.T.; Shimazu, S. Novel preparation method of bimetallic Ni-In alloy catalysts supported on amorphous alumina for the highly selective hydrogenation of furfural. Mol. Catal. 2018, 445, 52-60. [CrossRef]

16. Mironenko, R.M.; Belskaya, O.B.; Gulyaeva, T.I.; Nizovskii, A.I.; Kalinkin, A.V.; Bukhtiyarov, V.; Lavrenov, A.V.; Likholobov, V. Effect of the nature of carbon support on the formation of active sites in $\mathrm{Pd} / \mathrm{C}$ and $\mathrm{Ru} / \mathrm{C}$ catalysts for hydrogenation of furfural. Catal. Today 2015, 249, 145-152. [CrossRef]

17. Liu, L.; Lou, H.; Chen, M. Selective hydrogenation of furfural over Pt based and Pd based bimetallic catalysts supported on modified multiwalled carbon nanotubes (MWNT). Appl. Catal. A Gen. 2018, 550, 1-10. [CrossRef]

18. Aldosari, O.F.; Iqbal, S.; Miedziak, P.J.; Brett, G.L.; Jones, D.R.; Liu, X.; Edwards, J.K.; Morgan, D.J.; Knight, D.K.; Hutchings, G.J. Pd-Ru/TiO 2 catalyst-An active and selective catalyst for furfural hydrogenation. Catal. Sci. Technol. 2016, 6, 234-242. [CrossRef]

19. Chiara, P.; Laura, C.; Aguado-Molina, R.; Martin-Treceno, S.; Mark, A.K.; Cardenas-Lizana, F. Continuous furfuryl alcohol production via coupled dehydrogenation-hydrogenation over supported $\mathrm{Cu}$ and Au catalysts: A consideration of hydrogen generation and transfer. Mol. Catal. 2020, 492, 110912. [CrossRef]

20. Du, J.; Zhang, J.; Sun, Y.; Jia, W.; Si, Z.; Gao, H.; Tang, X.; Zeng, X.; Lei, T.; Liu, S.; et al. Catalytic transfer hydrogenation of biomass-derived furfural to furfuryl alcohol over in-situ prepared nano $\mathrm{Cu}-\mathrm{Pd} / \mathrm{C}$ catalyst using formic acid as hydrogen source. J. Catal. 2018, 368, 69-78. [CrossRef]

21. Villaverde, M.M.; Garetto, T.F.; Marchi, A.J. Liquid-phase transfer hydrogenation of furfural to furfuryl alcohol on $\mathrm{Cu}-\mathrm{Mg}-\mathrm{Al}$ catalysts. Catal. Commun. 2015, 58, 6-10. [CrossRef]

22. He, J.; Yang, S.; Riisager, A. Magnetic nickel ferrite nanoparticles as highly durable catalysts for catalytic transfer hydrogenation of bio-based aldehydes. Catal. Sci. Technol. 2018, 8, 790-797. [CrossRef]

23. Gong, W.; Chen, C.; Fan, R.; Zhang, H.; Wang, G.; Zhao, H. Transfer-hydrogenation of furfural and levulinic acid over supported copper catalyst. Fuel 2018, 231, 165-171. [CrossRef]

24. Guangzhi, X.; Chen, L.; Aiyun, H.; Shan, W.; Haijun, W. A novel synthesis of zirconium tannate with high stability: New insight into the structure of the catalyst for hydrogenation. Appl. Catal. A Gen. 2020, 602, 117666. [CrossRef] 
25. Jing, G.; Zhang, J.; Yazhuo, W.; Denian, L.; Hongyu, H.; Haoran, Y.; Yong, C. Efficient transfer hydrogenation of biomass derived furfural and levulinic acid via magnetic zirconium nanoparticles: Experimental and kinetic study. Ind. Crop. Prod. 2020, 145, 112133. [CrossRef]

26. Nagaiah, P.; Gidyonu, P.; Ashokraju, M.; Venkata, R.M.; Prathap, C.; David, R.B.; Seetha, R.R.K. Magnesium Aluminate Supported Cu Catalyst for Selective Transfer Hydrogenation of Biomass Derived Furfural to Furfuryl Alcohol with Formic Acid as Hydrogen Donor. Chemistry 2019, 4, 145-151. [CrossRef]

27. Ping, X.; Xu, X.; Shan, W.; Junjiang, Z.; Yujun, Z. One-pot synthesis of $\mathrm{LaFeO}_{3} @ \mathrm{C}$ composites for catalytic transfer hydrogenation reactions: Effects of carbon precursors. Appl. Catal. A Gen. 2020, 603, 117742. [CrossRef]

28. Okamoto, Y.; Imanaka, T.; Teranishi, S. Hydrogen Transfer Reaction between Alcohols and Acetone over metal oxides. Bul. Chem. Soc. Jpn. 1972, 45, 938-939. [CrossRef]

29. Maderuelo-Solera, R.; López-Asensio, R.; Cecilia, J.A.; Jiménez-Gómez, C.; García-Sancho, C.; Moreno-Tost, R.; Maireles-Torres, P. Catalytic transfer hydrogenation of furfural to furfuryl alcohol over calcined $\mathrm{MgFe}$ hydrotalcites. Appl. Clay Sci. 2019, 183, 105351. [CrossRef]

30. Wang, Y.; Zhu, W.; Sang, S.; Gao, L.; Xiao, G. Supported Cu catalysts for the hydrogenation of furfural in aqueous phase: Effect of support. Asia Pac. J. Chem. Eng. 2017, 12, 422-431. [CrossRef]

31. Fan, W.; Zehui, Z. Catalytic Transfer Hydrogenation of Furfural into Furfuryl Alcohol over Magnetic $\gamma-\mathrm{Fe}_{2} \mathrm{O}_{3} @ \mathrm{HAP}$ Catalyst. ACS Sustain. Chem. Eng. 2017, 5, 942-947.

32. Shi, R.; Wang, F.; Li, Y.; Huang, X.; Shen, W. A highly efficient $\mathrm{Cu} / \mathrm{La}_{2} \mathrm{O}_{3}$ catalyst for transfer dehydrogenation of primary aliphatic alcohols. Green Chem. 2010, 12, 108-113. [CrossRef]

33. Hu, Q.; Fan, G.; Yang, L.; Cao, X.; Zhang, P.; Wang, B.; Li, F. A gas-phase coupling process for simultaneous production of $\gamma$-butyrolactone and furfuryl alcohol without external hydrogen over bifunctional base-metal heterogeneous catalysts. Green Chem. 2016, 18, 2317-2322. [CrossRef]

34. Panagiotopoulou, P.; Vlachos, D. Liquid phase catalytic transfer hydrogenation of furfural over a Ru/C catalyst. Appl. Catal. A Gen. 2014, 480, 17-24. [CrossRef]

35. Zhang, J.; Chen, J. Selective Transfer Hydrogenation of Biomass-Based Furfural and 5-Hydroxymethylfurfural over Hydrotalcite-Derived Copper Catalysts Using Methanol as a Hydrogen Donor. ACS Sustain. Chem. Eng. 2017, 5, 5982-5993. [CrossRef]

36. Yang, X.; Meng, Q.; Ding, G.; Wang, Y.; Chen, H.; Zhu, Y.L.; Li, Y.W. Construction of novel Cu/ZnO- $\mathrm{Al}_{2} \mathrm{O}_{3}$ composites for furfural hydrogenation: The role of Al components. Appl. Catal. A Gen. 2018, 561, 78-86. [CrossRef]

37. Yan, K.; Chen, A.C. Efficient hydrogenation of biomass-derived furfural and levulinic acid on the facilely synthesized noble-metal-free Cu-Cr catalyst. Energy 2013, 58, 357-363. [CrossRef]

38. Elliot, J.C. Structure and Chemistry of the Apatites and Other Calcium Orthophosphates; Elsevier: Amsterdam, The Netherlands, 1994.

39. Zachary, D.Y.; Robert, J.D. Hydrogen transfer reactions relevant to Guerbet coupling of alcohols over hydroxyapatite and magnesium oxide catalysts. Catal. Sci. Technol. 2018, 8, 1722-1729.

40. Rodrigues, E.G.; Keller, T.C.; Mitchell, S.; Pérez-Ramírez, J. Hydroxyapatite, an exceptional catalyst for the gas-phase deoxygenation of bio-oil by aldol condensation. Green Chem. 2014, 16, 4870-4874. [CrossRef]

41. Hassib, T.; Samir, D.; Carolina, P.; Gérard, D. Copper loaded hydroxyapatite catalyst for selective catalytic reduction of nitric oxide with ammonia. Appl. Catal. B Environ. 2011, 107, 158-163.

42. Putrakumar, B.; Nagaraju, N.; Kumar, V.P.; Chary, K.V. Hydrogenation of levulinic acid to $\gamma$-valerolactone over copper catalysts supported on $\gamma-\mathrm{Al}_{2} \mathrm{O}_{3}$. Catal. Today 2015, 250, 209-217. [CrossRef]

43. Putrakumar, B.; Vijayanand, P.; Pavan, K.V.; Chary, K.V.R. Hydrogenation of biomass-derived levulinic acid to $\gamma$-valerolactone over copper catalysts supported on $\mathrm{ZrO}_{2}$. J. Chem. Technol. Biotechnol. 2015, 91, 769-776. [CrossRef]

44. Praliaud, H.; Mikhailenko, S.; Chajar, Z.; Primet, M. Surface and bulk properties of $\mathrm{Cu}-\mathrm{ZSM}-5$ and $\mathrm{Cu} / \mathrm{Al}_{2} \mathrm{O}_{3}$ solids during redox treatments. Correlation with the selective reduction of nitric oxide by hydrocarbons. Appl. Catal. B Environ. 1998, 16, 359-374. [CrossRef]

45. Dow, W.P.; Wang, Y.P.; Huang, T.J. Yitria-stabilized zirconia supported copper oxide catalyst: I. Effect of oxygen vacancy of support on copper oxide reduction. J. Catal. 1996, 160, 155-170. [CrossRef]

46. Kim, K.-H.; Ihm, S.-K. Characteristics of titania supported copper oxide catalysts for wet air oxidation of phenol. J. Hazard. Mater. 2007, 146, 610-616. [CrossRef] 
47. Aziz, M.; Jalil, A.; Wongsakulphasatch, S.; Vo, D.-V.N. Understanding the role of surface basic sites of catalysts in $\mathrm{CO}_{2}$ activation in dry reforming of methane: A short review. Catal. Sci. Technol. 2020, 10, 35-45. [CrossRef]

48. Gao, P.; Li, F.; Zhan, H.; Zhao, N.; Xiao, F.; Wei, W.; Zhong, L.; Wang, H.; Sun, Y. Influence of Zr on the performance of $\mathrm{Cu} / \mathrm{Zn} / \mathrm{Al} / \mathrm{Zr}$ catalysts via hydrotalcite-like precursors for $\mathrm{CO}_{2}$ hydrogenation to methanol. J. Catal. 2013, 298, 51-60. [CrossRef]

49. Isahak, W.N.R.W.; Zatil, A.C.R.; Mohamad, W.I.; Khomah, I.; Rahimi, M.Y.; Mohamed, W.M.H.; Mohd, A.Y. Adsorption-desorption of $\mathrm{CO}_{2}$ on different type of copper oxides surfaces: Physical and chemical attractions studies. J. CO2 Util. 2013, 2, 8-15. [CrossRef]

50. Chen, H.; Ruan, H.; Lu, X.; Fu, J.; Langrish, T.; Lu, X. Efficient catalytic transfer hydrogenation of furfural to furfuryl alcohol in near-critical isopropanol over $\mathrm{Cu} / \mathrm{MgO}-\mathrm{Al}_{2} \mathrm{O}_{3}$ catalyst. Mol. Catal. 2018, 445, 94-101. [CrossRef]

51. Chary, K.V.R.; Guggilla, V.S.; Dhachapally, N.; Kottapalli, K.S.; Bojja, S. Characterization and Reactivity of Copper Oxide Catalysts Supported on $\mathrm{TiO}_{2}-\mathrm{ZrO}_{2}$. J. Phys. Chem. B 2005, 109, 9437-9444. [CrossRef]

52. Gong, W.; Chen, C.; Zhang, Y.; Zhou, H.; Wang, H.; Zhang, H.; Zhang, Y.; Wang, G.; Zhao, H. Efficient Synthesis of Furfuryl Alcohol from H2-Hydrogenation/Transfer Hydrogenation of Furfural Using Sulfonate Group Modified Cu Catalyst. ACS Sustain. Chem. Eng. 2017, 5, 2172-2180. [CrossRef]

53. Wang, T.; Du, J.; Sun, Y.; Tang, X.; Wei, Z.-J.; Zeng, X.; Liu, S.-J.; Lin, L. Catalytic transfer hydrogenation of biomass-derived furfural to furfuryl alcohol with formic acid as hydrogen donor over CuCs-MCM catalyst. Chin. Chem. Lett. 2020. [CrossRef]

(C) 2020 by the authors. Licensee MDPI, Basel, Switzerland. This article is an open access article distributed under the terms and conditions of the Creative Commons Attribution (CC BY) license (http://creativecommons.org/licenses/by/4.0/). 